\title{
GMR
}

\section{Assessment of the rs4340 ACE gene polymorphism in acute coronary syndrome in a Western Mexican population}

\author{
A. Valdez-Haro ${ }^{1,2}$, Y. Valle ${ }^{1}$, E. Valdes-Alvarado ${ }^{1}$, F. Casillas-Muñoz ${ }^{1,2}$, \\ J.F. Muñoz-Valle', G.L. Reynoso-Villalpando ${ }^{1,2}$, H.E. Flores-Salinas ${ }^{3}$ and \\ J.R. Padilla-Gutiérrez ${ }^{1}$ \\ ${ }^{1}$ Instituto de Investigación en Ciencias Biomédicas, \\ Centro Universitario de Ciencias de la Salud, \\ Universidad de Guadalajara, Guadalajara, Jalisco, México \\ ${ }^{2}$ Post-Graduation en Genética Humana, \\ Centro Universitario de Ciencias de la Salud, \\ Universidad de Guadalajara, Guadalajara, Jalisco, México \\ ${ }^{3}$ Centro Médico Nacional de Occidente, \\ Instituto Mexicano del Seguro Social, Guadalajara, Jalisco, México \\ Corresponding author: J.R. Padilla-Gutiérrez \\ E-mail: imey_99@yahoo.com
}

Genet. Mol. Res. 16 (3): gmr16039779

Received July 17, 2017

Accepted August 30, 2017

Published September 27, 2017

DOI http://dx.doi.org/10.4238/gmr16039779

Copyright (C) 2017 The Authors. This is an open-access article distributed under the terms of the Creative Commons Attribution ShareAlike (CC BY-SA) 4.0 License.

\begin{abstract}
Acute coronary syndrome (ACS) is considered one of the main causes of death worldwide. Contradictory findings concerning the impact of the angiotensin-converting enzyme $(A C E)$ gene on cardiovascular diseases have been reported. Previous conclusions point out that the variability in results depends on ethnicity and genetic polymorphisms to determine the association of rs4340 polymorphisms of the $A C E$ gene and ACE circulating levels in ACS. Genotyping of rs4340 polymorphisms was performed in a total of 600 individuals from Western Mexico divided into two groups: the ACS and the control group (CG). The polymorphisms were identified by polymerase chain
\end{abstract}

Genetics and Molecular Research 16 (3): gmr16039779 
reaction. Serum ACE concentration was determined by enzyme-linked immunosorbent assay. D/D carriers had higher ACE levels than I/I carriers (3.6 vs $2.8 \mathrm{ng} / \mathrm{mL}, \mathrm{P}<0.0021)$ in the CG. The D/D genotype of the rs 4340 polymorphism is associated with higher ACE concentration levels; however, the polymorphism was not associated with ACS.

Key words: Acute coronary syndrome; Angiotensin-converting enzyme; Serum concentration; Genetic polymorphisms; Western Mexican population

\section{INTRODUCTION}

Acute coronary syndrome (ACS) is considered one of the main causes of death and emergency-service issues worldwide (WHO, available at http://www.who.int/mediacentre/ factsheets/fs310/en, accessed June 15, 2016). The ACS clinical spectrum includes the STsegment elevation myocardial infarction (STEMI), the non-ST-segment elevation myocardial infarction (NSTEMI), and unstable angina (UA) (Rajpurohit et al., 2015). The pathophysiology of ACS involves thrombotic, inflammatory, oxidative, and metabolic processes. Infiltrating inflammatory cells interact with the intrinsic arterial cells, promoting lesion formation and complications (Libby et al., 2011). The angiotensin-converting enzyme (ACE) gene contributes widely to atheroma formation, inflammatory process, and thrombosis, leading to acute myocardial ischemia (Curzen and Fox, 1997).

The $A C E$ gene is located on chromosome 17q23 and contains 26 exons and encodes two enzymes, namely, sACE (somatic) and tACE (testicular). The ACE protein belongs to the dipeptidyl-carboxypeptidases of the metalloprotease family, which is involved in the conversion of the angiotensin I (Ang I) decapeptide into octapeptide angiotensin II (Ang II). The latter is a powerful vasopressor that regulates blood pressure and salt-water homeostasis, mainly through aldosterone biosynthesis (Hubert et al., 1991). ACE is shed from the cell surface by a disintegrin and metalloproteinase domain-family alpha secretase, releasing the soluble form. In sACE, the cleavage site is arginine 1203 and serine 1204, 24 residues proximal to the membrane-anchoring domain (Parkin et al., 2004). Serum ACE concentration in normal subjects is reported within a wide range, being affected by age, gender, and ethnicity (McKenzie et al., 1995; Villard et al., 1996; Fagyas et al., 2014). Some polymorphisms could alter the transcription rate and serum concentration of protein, thus modifying ACS susceptibility. The 287-bp insertion/deletion ACE polymorphism (rs4340) is located in the 16th intron of the $A C E$ gene. D-allele carriers have demonstrated increased Ang I-Ang II conversion and ACE concentration, with an increased predisposition for myocardial infarction and coronary heart disease (Cambien et al., 1994; Kondo et al., 2015). To the best of our knowledge, this polymorphism has not been studied regarding ACS susceptibility in our population.

\section{MATERIAL AND METHODS}

Genotyping was performed in 300 ACS patients and 300 healthy individuals (the control group, CG). Patients with ACS were diagnosed by the criteria of the American College of Cardiology (ACC) (Cannon et al., 2013). Classical risk factors, defined according to the ACC, were categorized as present or absent. The inclusion criteria for CG were the absence of ischemic cardiopathy and infectious diseases. The controls were similar in age to the cases,

Genetics and Molecular Research 16 (3): gmr16039779 
without medical treatment. Subjects were recruited from the Hospital de Especialidades del Centro Médico Nacional de Occidente del Instituto Mexicano del Seguro Social (CMNO, IMSS). Only individuals who had been born in Western Mexico and for three generations including their own were considered.

All subjects and patients agreed to participate in the study and signed an informed written consent. The study was performed following the ethical guidelines of the 2013 Declaration of Helsinki and with the approval of the Ethics Committee of the Centro Universitario de Ciencias de la Salud (CUCS), Universidad de Guadalajara (UdeG). Genomic DNA was extracted from peripheral blood according to the salting out method (Miller et al., 1988). The analysis was performed with polymerase chain reaction (PCR); this polymorphism was subjected to two rounds of amplification. The primer sequences were the following: forward (5'-CTG GAG ACC ACT CCC ATC CTT TCT-3') and reverse (5'-GAT GTG GCC ATC ACA TTC GTC AGA T-3'). The presence of allele I or D resulted in a 490- or a 190bp fragment. PCR amplification was carried out in a total volume of $15 \mu \mathrm{L}$ containing $5 \mu \mathrm{g}$ genomic DNA, 1.25 U/L Taq DNA polymerase (Invitrogen Life Technologies), 1X supplied buffer enzyme, $20 \mu \mathrm{M}$ of each oligonucleotide, $2.5 \mathrm{mM} \mathrm{MgCl}_{2}$, and $2.5 \mathrm{mM}$ dNTP (Invitrogen Life Technologies). Thermocycling conditions had an initial denaturation step of $3 \mathrm{~min}$ at $94^{\circ} \mathrm{C}$, followed by 30 cycles of $20 \mathrm{~s}$ each at $94^{\circ}, 62^{\circ}$, and $72^{\circ} \mathrm{C}$, with a final extension step of 10 min at $72^{\circ} \mathrm{C}$.

Due to preferential amplification of the smaller allele (D), D homozygous carriers underwent a second amplification with the following insertion-specific primers: forward (5'-TGG GAC CAG AGC GCC CGC CAC TAC-3') and reverse (5'-TCG CCA GCC CTC CCAT GCC CAT AA-3') to discriminate heterozygotes, obtaining a 335-bp band if one allele was present. For amplification control in this assay, tumor necrosis factor alpha $(\mathrm{TNF}-\alpha)$ primer sequences were utilized: forward (5'-TAT GTG ATG GAC TCA CCA GG3') and reverse (5'-CCT CTA CAT GGC CCT GTC TT-3'); the amplicon was $264 \mathrm{bp}$. PCR was carried out in a total volume of $15 \mu \mathrm{L}$ containing $5 \mathrm{~g}$ genomic DNA, $1.25 \mathrm{U} / \mu \mathrm{L}$ Taq DNA polymerase (Invitrogen Life Technologies), 1X supplied buffer enzyme, $20 \mu \mathrm{M}$ of each oligonucleotide, $2.5 \mathrm{mM} \mathrm{MgCl}$, and $2.5 \mathrm{mM}$ dNTP (Invitrogen Life Technologies). Thermocycling conditions comprised an initial denaturation step of $5 \mathrm{~min}$ at $94^{\circ} \mathrm{C}$, followed by 30 cycles of $20 \mathrm{~s} \mathrm{each}$ at $94^{\circ}, 66^{\circ}$, and $72^{\circ} \mathrm{C}$, with a final extension step of $1 \mathrm{~min}$ at $72^{\circ} \mathrm{C}$. The amplicon was visualized by silver-stained polyacrylamide gels (29:1). ACE levels were measured in duplicate using serum using the enzyme-linked immunosorbent assay according to the manufacturer's specifications (R\&D Systems, Minneapolis, MN, USA). The ACE range was $156-10,000 \mathrm{pg} / \mathrm{mL}$, and the sensitivity of the assay was $<5 \mathrm{pg} / \mathrm{mL}$. The ACE concentration was calculated using a four-parameter logistic (4-PL) curve fit. The coefficients of variation fell within acceptable ranges $(<10 \%)$.

The SPSS statistical software package version 20.0 was employed for statistical analysis. Continuous variables are reported as means \pm standard deviation (SD). The Kolmogorov-Smirnov test and sample size were considered to categorize parametric tests (Student $t$-test and analysis of variance) and non-parametric tests (Spearman correlation, Kruskal-Wallis test, and Mann-Whitney U-test). Qualitative data and Hardy-Weinberg equilibrium were analyzed with the chi-square or the Fisher exact test, when applicable. Allele frequencies were determined by the counting method. Recessive allele model was tested with the chi-square test. The significance level was $<0.05$ (Lander and Kruglyak, 1995). The measurement of association was the odds ratio.

Genetics and Molecular Research 16 (3): gmr16039779 


\section{RESULTS}

CG subjects and patients with ACS had a mean age of 55.4 and 62.7 years, respectively (Table 1). For the ACS group, the male was three times more frequent than female gender; cardiac biomarker values, including troponin I, creatine phosphokinase (CPK), and CPK-MB were increased. Similarly, plasmatic glucose was above normal values. The most prevalent risk factor was hypertension, followed by type 2 diabetes mellitus (DM2) and smoking. Treatment included administration of antiplatelet (acetylsalicylic acid, clopidogrel), heparin, statins (atorvastatin), and antihypertensive drugs (Table 2).

\begin{tabular}{|c|c|c|c|c|c|}
\hline Parameters & ACS & (Average \pm SD) & CG & (Average \pm SD) & Normal range \\
\hline Ratio (M/F) & 3.21 & & 1.09 & & \\
\hline Age (years) & 62.7 & \pm 10.9 & 55.4 & \pm 10.9 & \\
\hline Glucose (mg/dL) & 138.5 & \pm 57.7 & 117.5 & \pm 87.2 & $70-100$ \\
\hline Cholesterol (mg/dL) & 118.9 & \pm 39.1 & 165.6 & \pm 43.6 & $150-199$ \\
\hline Triglycerides (mg/dL) & 91.9 & \pm 35.3 & 116.3 & \pm 63.0 & $<200$ \\
\hline LDL $(\mathrm{mg} / \mathrm{dL})$ & 45.3 & \pm 19.1 & 73.8 & \pm 32.3 & $<130$ \\
\hline $\mathrm{HDL}(\mathrm{mg} / \mathrm{dL})$ & 21.0 & \pm 11.9 & 40.5 & \pm 20.0 & $>40$ \\
\hline $\mathrm{CPK}(\mu / \mathrm{L})$ & 859.9 & \pm 1403.6 & - & - & $2.4-19.5$ \\
\hline CPK-MB $(\mu / \mathrm{L})$ & 108.9 & \pm 160.8 & - & - & $49-397$ \\
\hline Troponin I (ng/ml) & 7.1 & \pm 14.5 & - & - & $<0.04$ \\
\hline
\end{tabular}

LDL: low-density lipoprotein; HDL: high-density lipoprotein; CK: creatine phosphokinase; CK-MB: creatine phosphokinase MB; SD: standard deviation; M: male; F: female.

Table 2. Medical treatment and risk factor prevalence in the ACS patients.

\begin{tabular}{l|c|c|c|c|c}
\hline Treatment & $\mathrm{N}$ & $(\%)$ & Risk factor & N & $(\%)$ \\
\hline ARA-II & 55 & $(16.5)$ & IFH & 145 & $(42.4)$ \\
\hline Acetylsalicylic acid & 326 & $(95.3)$ & Dyslipidemia & 147 & $(43.6)$ \\
\hline CCB & 41 & $(12.3)$ & DM2 & 178 & $(52.0)$ \\
\hline BB & 196 & $(57.3)$ & COPD & 3 & $(0.9)$ \\
\hline Clopidogrel & 241 & $(72.2)$ & HBP & 226 & $(66.1)$ \\
\hline Statins & 269 & $(79.9)$ & RHA & 51 & $(14.9)$ \\
\hline Heparin & 262 & $(56.6)$ & Overweight & 139 & $(26.9)$ \\
\hline ACE inhibitors & 189 & $(43.6)$ & Smoking & 172 & $(40.6)$ \\
\hline Nitrates & 146 & & $50.3)$ \\
\hline
\end{tabular}

ARA-II: receptor antagonists of angiotensin II; CCB: calcium channel blockers; BB: beta blockers; IFH: inherited family history; DM2: type 2 diabetes mellitus; COPD: chronic obstructive pulmonary disease; HBP: high blood pressure, RHA: recurrent heart attack.

The genotype distribution was performed by Hardy-Weinberg equilibrium expectations $(\mathrm{P}=0.64)$. Allele and genotype frequencies were similar between groups (Table 3). D allele frequency was $59.6 \%$ in the CG and 53.9\% in ACS. In the recessive model, a discrete difference was found $(\mathrm{OR}=1.445 ; \mathrm{P}=0.044)$. The risk for $\mathrm{D}$ allele prevalence in the $\mathrm{CG}$ was similar $(\mathrm{P}>0.01)$ compared with other populations such Mexican Pima (46\%), European (51\%), and Hispanic from the USA (45\%) although different from African (75\%), Asian (72\%), and Yucatec Mayas (27\%) (http://alfred.med.yale.edu/alfred; accessed June 10, 2016).

Genetics and Molecular Research 16 (3): gmr16039779 
Table 3. Allele and genotype distribution of the ACE polymorphism.

\begin{tabular}{l|c|c|c|c}
\hline $11689 \mathrm{I} / \mathrm{D}(\mathrm{rs} 4340)$ & ACS N $=300(\%)$ & CG N $=300(\%)$ & OR*(CI) & P value \\
\hline Allele & & & & \\
\hline$I$ & $277(46.1)$ & $301(40.4)$ & - & NS \\
\hline$D$ & $323(53.9)$ & $444(59.6)$ & $1.174(0.936-1.472)$ & - \\
\hline Genotype & & & & NS \\
\hline$I / I$ & $71(23.6)$ & $73(24.0)$ & - & NS \\
\hline$I / D$ & $135(45.0)$ & $155(51.7)$ & $0.896(0.600-1.336)$ & \\
\hline$D / D$ & $94(31.3)$ & $72(24.0)$ & $1.342(0.857-2.105)$ & \\
\hline Recessive model & & & & - \\
\hline$I / D+D / D$ & $229(76.3)$ & $227(75.7)$ & - & 0.044 \\
\hline$I / I$ & $71(23.7)$ & $73(24.3)$ & $1.445(1.008-2.071)$ & \\
\hline
\end{tabular}

CG: control group; ACS: acute coronary syndrome; OR: odds ratio; CI: confidence interval.

The median ACE concentration was similar between ACS and CG (3.5 vs $3.04 \mathrm{ng} /$ $\mathrm{mL}$ ). Likewise, the ACE concentration was similar to clinical spectrum in patients (Figure 1). Neither age (less or higher than 55 years) nor gender affected the ACE concentration.
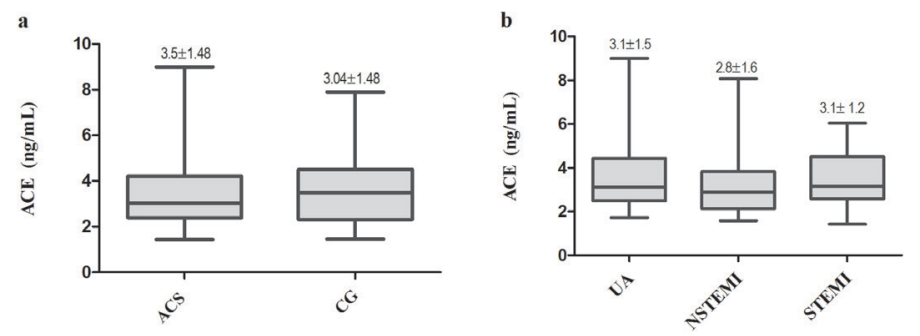

Figure 1. ACE serum concentration in the study groups and ACS clinical diagnosis. a. ACE concentration by the studied group. b. ACE concentration by clinical diagnosis in ACS. ACE: angiotensin-converting enzyme; ACS: acute coronary syndrome; CG: control group; NSTEMI: non-ST-segment elevation myocardial infarction; STEMI: ST-segment elevation myocardial infarction; UA: unstable angina. Boxes indicate the interquartile range (IQR) with the median; whiskers are minimal and maximal values. Medians (numbers above the upper bar) were compared by the Mann-Whitney U-test.

To test the influence of the polymorphisms on ACE concentration, we stratified data according to genotypes in both groups. The D/D homozygous displayed higher ACE median concentrations than those in I/I carriers (3.6 vs $2.8 \mathrm{ng} / \mathrm{mL}, \mathrm{P}<0.0021)$ in the CG (Figure 2a), while in patients, the median ACE concentration was similar by genotype (Figure $2 b$ ).
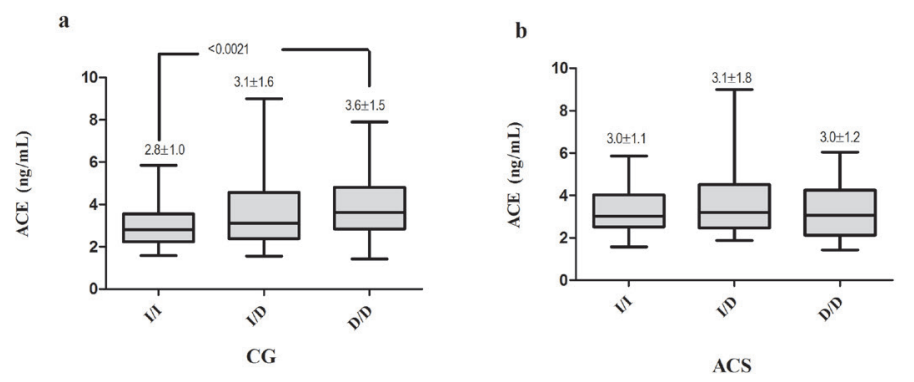

Figure 2. Comparison between ACE genotypes and ACE serum concentration. a. Influence of the rs4340 polymorphism on ACE concentration in the CG. b. Influence of the rs 4340 polymorphism on ACE concentration in ACS. ACE: angiotensin-converting enzyme; ACS: acute coronary syndrome; CG: control group. Boxes indicate the interquartile range (IQR) with the median; whiskers are minimal and maximal values. Medians (numbers above the upper bar) were compared by the Mann-Whitney U-test.

Genetics and Molecular Research 16 (3): gmr16039779 


\section{DISCUSSION}

Contradictory findings concerning the impact of the $A C E$ gene on cardiovascular diseases have been reported. The main prior conclusions point out that the variability in results depends on ethnicity and genetic polymorphisms (Sayed-Tabatabaei et al., 2006). The main risk factors in our patients with ACS were hypertension (66.1\%), smoking (50.3\%), DM2 (52\%), and dyslipidemia (43.6\%). Previous reports described the rise of hypertension in patients with myocardial infarction and even an increase in younger age groups (INEGI, available at http://www.inegi. org.mx/inegi/contenidos/espanol/prensa/Contenidos/estadisticas/2013, accessed May 30, 2016; García Castillo et al., 2005). As can be noted, the risk factors are present in close to or more than one-half of the cases, contributing to a propitious environmental framework in its development. Biochemical parameters revealed a slight elevation of glucose; this increase has been attributed to the activation of inflammatory mediators, such as nuclear factor-kappa beta, which induces a transient increase during the acute event (Arnold et al., 2014). CCPK and Troponin I values were above the normal range ( $>44$ times), which is expected in that they are a core part of the pathology diagnosis. Due to its high cardiospecificity, Troponin I has become the cornerstone for risk stratification in ACS because the remainder of cardiac biomarkers can be altered by other conditions involving muscle injury or trauma (Cengiz et al., 1991; Tang et al., 2008).

A previous study in Mexicans with hypertension without ACE inhibitors reported a serum concentration of ACE between 2.6 and $3.8 \mathrm{ng} / \mathrm{mL}$, stratified by low- and high-haplotype risk, respectively (Martínez-Rodriguez et al., 2013). These concentrations are nearly similar to those reported in the present study; however, the study design was different from ours, and none of the polymorphisms studied in our study were included. We had clear results that serum ACE concentration in ACS is biased by ACE inhibitors and Ang II receptor antagonists (ARAII); however, ethical principles would not allow us to withdraw consumption of the drug from our patients. Intriguingly, modifiers of ACE treatment did not show the enzyme concentration. It is probable that the sample size of patients who were not receiving these drugs does not permit us to conduct a reliable analysis; consequently, this factor is an intervening variable that should be considered in future studies.

Regarding the genetic association of this polymorphism with ACS, we did not find evidence of such an association. Conversely, Chen et al. (2012) found the D/D genotype associated with ACS and disease severity in Taiwan population. Besides, other studies have demonstrated a consistent association of the polymorphism with myocardial infarction or coronary artery disease (Keavney et al., 2000; Kaiser Jamil, 2009; Vaisi-Raygani et al., 2010). The relationship of this polymorphism with cardiovascular disease has been correlated with its functional effect. The $\mathrm{D}$ allele is proposed to remove a gene expression repressor site; thus, the carriers of this allele have higher ACE levels, which are linked with adverse cardiovascular effects (Rosatto et al., 1999). Rigat et al. (1990) reported that ACE activity is proportional to the serum ACE concentration and that the rs 4340 polymorphism accounts for one-half of the variance observed in ACE serum levels. Similar to that previously described, we found that D/D carriers had higher ACE concentration than I/I genotype in controls. With these results, we confirmed that the $\mathrm{D}$ allele determines higher concentrations of the enzyme, although we were not able to confirm the increased ACS risk regarding this polymorphism.

In conclusion, the $\mathrm{D} / \mathrm{D}$ genotype of the rs 4340 polymorphism is associated with higher ACE concentrations; however, the polymorphism is not a risk factor for the development of ACS in a western Mexican population.

Genetics and Molecular Research 16 (3): gmr16039779 


\section{Conflicts of interest}

The authors declare no conflict of interest.

\section{ACKNOWLEDGMENTS}

The authors would like to thank all volunteers who participated in this study.

\section{REFERENCES}

Arnold SV, Lipska KJ, Li Y, McGuire DK, et al. (2014). Prevalence of glucose abnormalities among patients presenting with an acute myocardial infarction. Am. Heart J. 168: 466-470.e1. https://doi.org/10.1016/j.ahj.2014.06.023

Cambien F, Costerousse O, Tiret L, Poirier O, et al. (1994). Plasma level and gene polymorphism of angiotensin-converting enzyme in relation to myocardial infarction. Circulation 90: 669-676. https://doi.org/10.1161/01.CIR.90.2.669

Cannon CP, Brindis RG, Chaitman BR, Cohen DJ, et al.; American College of Cardiology Foundation/American Heart Association Task Force on Clinical Data Standards; American College of Emergency Physicians; Emergency Nurses Association; National Association of Emergency Medical Technicians; National Association of EMS Physicians; Preventive Cardiovascular Nurses Association; Society for Cardiovascular Angiography and Interventions; Society of Cardiovascular Patient Care; Society of Thoracic Surgeons (2013). 2013 ACCF/AHA key data elements and definitions for measuring the clinical management and outcomes of patients with acute coronary syndromes and coronary artery disease: a report of the American College of Cardiology Foundation/American Heart Association Task Force on Clinical Data Standards (Writing Committee to Develop Acute Coronary Syndromes and Coronary Artery Disease Clinical Data Standards). Circulation 127: 1052-1089. https://doi.org/10.1161/CIR.0b013e3182831a11

Cengiz K, Alvur M and Dindar U (1991). Serum creatine phosphokinase, lactic dehydrogenase, estradiol, progesterone and testosterone levels in male patients with acute myocardial infarction and unstable angina pectoris. Mater. Med. Pol. 23: 195-198.

Chen YH, Liu JM, Hsu RJ, Hu SC, et al. (2012). Angiotensin converting enzyme DD genotype is associated with acute coronary syndrome severity and sudden cardiac death in Taiwan: a case-control emergency room study. BMC Cardiovasc. Disord. 12: 6. https://doi.org/10.1186/1471-2261-12-6

Curzen NP and Fox KM (1997). Do ACE inhibitors modulate atherosclerosis? Eur. Heart J. 18: 1530-1535. https://doi. org/10.1093/oxfordjournals.eurheartj.a015132

Fagyas M, Úri K, Siket IM, Daragó A, et al. (2014). New perspectives in the renin-angiotensin-aldosterone system (RAAS) III: endogenous inhibition of angiotensin converting enzyme (ACE) provides protection against cardiovascular diseases. PLoS One 9: e93719. https://doi.org/10.1371/journal.pone.0093719

García Castillo A, Jerjes Sánchez C, Martínez Bermúdez P, Azpiri López JR, et al. (2005). RENASICA II. Mexican Registry of Acute Coronary syndromes. Arch. Cardiol. Mex. 75: 6-19.

Hubert C, Houot AM, Corvol P and Soubrier F (1991). Structure of the angiotensin I-converting enzyme gene. Two alternate promoters correspond to evolutionary steps of a duplicated gene. J. Biol. Chem. 266: 15377-15383.

Kaiser Jamil RS (2009). Implications of I/D (rs4340) polymorphism in CAD among South Indian population. Int. J. Med. Med. Sci. 1: 151-157.

Keavney B, McKenzie C, Parish S, Palmer A, et al. (2000). Large-scale test of hypothesised associations between the angiotensin-converting-enzyme insertion/deletion polymorphism and myocardial infarction in about 5000 cases and 6000 controls. International Studies of Infarct Survival (ISIS) Collaborators. Lancet 355: 434-442. https://doi. org/10.1016/S0140-6736(00)82009-7

Kondo H, Ninomiya T, Hata J, Hirakawa Y, et al. (2015). Angiotensin I-converting enzyme gene polymorphism enhances the effect of hypercholesterolemia on the risk of coronary heart disease in a general Japanese population: the hisayama study. J. Atheroscler. Thromb. 22: 390-403. https://doi.org/10.5551/jat.24166

Lander E and Kruglyak L (1995). Genetic dissection of complex traits: guidelines for interpreting and reporting linkage results. Nat. Genet. 11: 241-247. https://doi.org/10.1038/ng1195-241

Libby P, Ridker PM and Hansson GK (2011). Progress and challenges in translating the biology of atherosclerosis. Nature 473: 317-325. https://doi.org/10.1038/nature10146

Martínez-Rodríguez N, Posadas-Romero C, Villarreal-Molina T, Vallejo M, et al. (2013). Single nucleotide polymorphisms of the angiotensin-converting enzyme $(A C E)$ gene are associated with essential hypertension and increased ACE enzyme levels in Mexican individuals. PLoS One 8: e65700. https://doi.org/10.1371/journal.pone.0065700

Genetics and Molecular Research 16 (3): gmr16039779 
McKenzie CA, Julier C, Forrester T, McFarlane-Anderson N, et al. (1995). Segregation and linkage analysis of serum angiotensin I-converting enzyme levels: evidence for two quantitative-trait loci. Am. J. Hum. Genet. 57: 1426-1435.

Miller SA, Dykes DD and Polesky HF (1988). A simple salting out procedure for extracting DNA from human nucleated cells. Nucleic Acids Res. 16: 1215. https://doi.org/10.1093/nar/16.3.1215

Parkin ET, Turner AJ and Hooper NM (2004). Secretase-mediated cell surface shedding of the angiotensin-converting enzyme. Protein Pept. Lett. 11: 423-432. https://doi.org/10.2174/0929866043406544

Rajpurohit N, Ayaz SZ, Yee J, Khan MA, et al. (2015). Review of acute coronary syndromes: diagnosis and management of unstable angina and non ST-elevation myocardial infarction. S. D. Med. 68: 71-75.

Rigat B, Hubert C, Alhenc-Gelas F, Cambien F, et al. (1990). An insertion/deletion polymorphism in the angiotensin I-converting enzyme gene accounting for half the variance of serum enzyme levels. J. Clin. Invest. 86: 1343-1346. https://doi.org/10.1172/JCI114844

Rosatto N, Pontremoli R, De Ferrari G and Ravazzolo R (1999). Intron 16 insertion of the angiotensin converting enzyme gene and transcriptional regulation. Nephrol. Dial. Transplant. 14: 868-871. https://doi.org/10.1093/ndt/14.4.868

Sayed-Tabatabaei FA, Oostra BA, Isaacs A, van Duijn CM, et al. (2006). ACE polymorphisms. Circ. Res. 98: 1123-1133. https://doi.org/10.1161/01.RES.0000223145.74217.e7

Tang WHW, Francis GS, Morrow DA, Newby LK, et al.; NACB Committee (2008). National Academy of Clinical Biochemistry Laboratory Medicine Practice Guidelines: clinical utilization of cardiac biomarker testing in heart failure. Clin. Biochem. 41: 210-221. https://doi.org/10.1016/j.clinbiochem.2007.07.002

Vaisi-Raygani A, Ghaneialvar H, Rahimi Z, Nomani H, et al. (2010). The angiotensin converting enzyme D allele is an independent risk factor for early onset coronary artery disease. Clin. Biochem. 43: 1189-1194. https://doi. org/10.1016/j.clinbiochem.2010.07.010

Villard E, Tiret L, Visvikis S, Rakotovao R, et al. (1996). Identification of new polymorphisms of the angiotensin I-converting enzyme $(A C E)$ gene, and study of their relationship to plasma ACE levels by two-QTL segregationlinkage analysis. Am. J. Hum. Genet. 58: 1268-1278.

Genetics and Molecular Research 16 (3): gmr16039779 